\title{
Collaboration with and without Coauthorship: Rocket Science Versus Economic Science
}

\author{
by \\ William A. Barnett ${ }^{1}$ \\ University of Kansas, Lawrence, Kansas, and Center for Financial Stability, N. Y. City \\ Invited essay prepared for the book, Michael Szenberg and Lall Ramrattan (eds.), Intellectual \\ Collaborative Experiences, Cambridge University Press, forthcoming.
}

June 23,2015

\section{Introduction}

My intellectual origins as an economist are somewhat different from those of most economists. While the words "rocket scientist" are often loosely associated with some economists, I really was a rocket scientist. After receiving my BS in engineering from MIT, before returning to graduate school to acquire my PhD in statistics and economics, I worked as a systems development engineer for Rocketdyne in Los Angeles on the development of the F-1 booster rocket engine for Apollo. That rocket engine, producing 1.5 million points of thrust, was, and still is, the most powerful rocket engine ever built. The engine was used in a cluster of five in the first stage of the Apollo launch vehicle, which was 363 feet tall and weighed six million pounds. The first stage raised the vehicle to forty miles of altitude at Mach 7 in two and one-half minutes, while burning four and one-half million pounds of propellant.

For the benefit of readers not familiar with Rocketdyne, I provide the first paragraph of the back cover of the authoritative book, Kraemer (2005):

\footnotetext{
${ }^{1}$ I have benefitted from comments by Steve Hanke, Michael Belongia, Stephen Spear, Lawrence Goodman, Guo Chen, William Poole, and Joshua Rosenbloom.
} 
"From the first American orbiting satellite, to Neil Armstrong, and Buzz Aldrin's historical walk on the Moon, virtually every major achievement in American Space history was made possible by a Rocketdyne engine. And, that record has stood true for over forty years, as today the Space Shuttle program continues to rely on engines designed and built by Rocketdyne. This book is the story behind that unprecedented accomplishment. It is the chronicle of success of one team of rocket pioneers who propelled the American space program from trailing the Soviet Union in the 1950s and early 1960s into today's position of leadership in space. It is a story of heroes and even a few villains, but mostly it is a story of triumphant success in the human venture into space. ... The rest of the book is a chronicle of both the author's own memories and experiences as a member of the Rocketdyne team, as well as those of other key members of this elite group, including: ... Bob Biggs .... This book is a true testament to the human spirit -- and to a dedicated and determined team of aerospace engineers who launched a nation into Space."

Real "rocket scientists" virtually never work alone. A modern rocket engine is far too complicated to be developed by one person. Many major advancements in science were produced by Rocketdyne and other contractors working on Apollo, and those contractors sought to employ the most sophisticated engineers and scientists. While I did work on major advances in engineering in collaboration with other engineers, I never published a paper while employed at Rocketdyne. In fact, if I had attempted to do so, I would have gotten into serious trouble. Everything I did at Rocketdyne was classified as "secret." My security clearance explicitly prohibited me from publishing any results or discoveries produced from my work.

While the aerospace industry has long been a major source of unpublished advances in science and engineering, Silicon Valley has more recently become a world center of scientific and engineering advances. The engineers and scientists working there are usually not permitted to publish their work, which is viewed as proprietary to their firms. We academics tend to equate collaboration and coauthorship, as a result of academia's emphasis on publication. That view is likely reflected by other essays in this volume. But in the physical sciences, a large percent of the most important collaborative scientific research is not, and cannot be, published.

Since my intellectual origins as a scientist go back to my experiences at Rocketdyne, at which all research and development are necessarily collaborative, my publications, since becoming an economist, have usually been coauthored, often with graduate students. But a few of my most important papers were solely authored, such as my paper, Barnett (1980). In that paper, I originated the Divisia monetary aggregates and the modern literature on aggregation theoretic aggregation over financial and monetary assets. 


\section{Rocket Science}

One objective of this essay to contrast my experience as a collaborative rocket scientist with my experiences as an academic economist. Indeed, the contrast is sometimes stark.

My immediate supervisor at Rocketdyne was a brilliant engineer by the name of Robert E. (Bob) Biggs. I have been out of contact with him, since I became an economist, although I did see him on television recently being interviewed about the space program. He rose to high levels within that industry, as evidenced by his mention among the "elites" in the back cover quotation reprinted above from Kraemer (2005). You can find his dramatic biography and a paper by him in Fisher and Rahman (2009, pp. 15-26). His paper comprises chapter 1 of that book and is entitled, "Rocketdyne F-1 Saturn V First Stage Engine.” His contributions to the development of the F-1 rocket engine and subsequently to the Space Shuttle main rocket engine were major. When I knew him, he was a very unusual person, early in his career. He had no college degrees, but took night courses at UCLA in mathematics. He had become exceptionally innovative in the use of the Laplace transform in solving difficult problems, but that was by no means his only area of conspicuous expertise. He was very impressive and extraordinarily determined. One of his statements to me at that time was that if coins ever fell out of his pocket at the coffee vending machine, he would leave the coins on the floor, since his time was too valuable to be wasted picking up coins.

There were situations under which I had to talk with machinists in the factory about possible sources of unsolved problems in design or about production of a device to be used in an experiment. One of the factory workers was an especially nice guy, who I found to be very helpful, when I needed something done by a machinist. I told Bob about him. Bob's reply was "I hate nice guys." Bob was likely the most brilliant engineer I knew at Rocketdyne. But would you expect such a person to be welcomed into academia as a professor? Similarly some of the best known and most successful scientists in Silicon Valley have no college degrees and have never published a paper in a peer reviewed journal. Indeed real rocket science and economic "rocket scientists" in academia can be very different.

Bob Biggs' immediate supervisor was the F-1 Development Project Engineer, Stuart Mulliken, who in turn worked for the F-1 Project Engineer. The position of Project Engineer is a very powerful position, since he is in control of all of the engineering being done on the engine, with the Development Project Engineer being in charge of the system development engineering on the engine. I worked directly in the Project Office, which included a couple of dozen engineers who were at the center of the 
F-1 development engineering. Many staff specialists in such fields as thermodynamics and fluid dynamics worked in support groups that did not report directly to a project office and could work on any of the rocket engines being developed by the firm, such as the upper stage J-2 or H-1 rocket engines for Apollo. But any work done on the F-1 rocket engine by such a staff support engineer was under the control of the F-1 Project Engineer, who thereby had direct or indirect control over the work of hundreds of the firm's most brilliant engineers. In my work in the F-1 System Project Office, I often needed to be able to consult with experts in the staff support groups, especially regarding problems with the troublesome turbopumps, which pumped the fuel and liquid oxygen into the engine's thrust chamber. Bob Biggs knew all of the staff support experts and invariably referred me to the relevant ones, when I needed specialized assistance.

In addition to being a fine engineer, Stuart Mulliken had an exceptionally outgoing and likeable personality, making it easy for him to gain the voluntary and cooperative support of any of the firm's engineers, when needed. He was the best liked engineer I knew at Rocketdyne. I am sure he did not dislike "nice guys" and would have taken the few seconds to pick up any coins he might have dropped at the coffee vending machine. To my astonishment, when he was at the peak of his power and influence at Rocketdyne, he resigned to become a realtor in Los Angeles. Although he was not trained as an economist, his decision, in retrospect, was based upon a very insightful economic decision. This happened during the 1960s, when real estate was inexpensive in Los Angeles. Many people from the northern U.S. were moving to Los Angeles, because of the inexpensive real estate. The usual explanation of the low L. A. housing prices at that time was the lack of need to excavate to build basements for furnaces, since the winters were so mild. For example, I was offered the opportunity to buy a house in Beverly Hills at a low price. I declined, and continued renting an apartment, during the time I lived in California. Evidently my insight into regional economic trends was significantly inferior to Stuart Mulliken's. Considering what has happened to real estate prices since the 1960, I assume that Stuart must now be a very wealthy man.

\section{Nonlinearity}

In terms of methodology, the clearest contrasts between my work at Rocketyne and my subsequent work as an economist are in terms of the degree of emphasis on nonlinearity and especially emphasis on measurement. At Rocketdyne, I had available vast amounts of experimental data, sometimes acquired at my request. We tested the F-1 rocket engine at Edwards Air Force Base. Rocketdyne's primary test facilities were in the beautiful Santa Susana Mountains at the western border 
of the San Fernando Valley. That facility was very conveniently located, since Rocketdyne's engineers were in buildings in Canoga Park at the west end of the San Fernando Valley.

The 2,850-acre former rocket engine test site is now contaminated by a vast amount of radioactive isotopes and toxic chemicals and is currently undergoing one of the country's most challenging cleanup efforts. But the awesome, thunderous roar produced by the F-1 engine was so overwhelming, that it could have been heard from that high mountain down into the Valley, where residents would have complained or been alarmed. As a result, we instead used a highly secure location in Edwards Air Force Base, far from the nearest city in the central California dessert. Since the United States was under the incorrect impression that it was in a race with the Soviet Union to put astronauts on the moon, Rocketdyne had easy access to enormous amounts of money from NASA contracts to run tests of our rocket engines.

It was clear to me from the results of those tests, that linear models could not accurately fit the data. With availability of only early generation mainframe computers, estimation of nonlinear models was challenging. But I did have access to a staff of statisticians to help. While estimation of nonlinear models is now much easier than at that time and while the economy is a much more complicated system than any rocket engine, I remain somewhat uncomfortable about the heavy use of linear econometric models by econometricians. However, that difference is minor compared with the difference in emphasis on measurement.

\section{Measurement}

The different emphasis on measurement is very major, especially between macroeconomics and rocket science. In fact the disturbingly large magnitude of that gap motivated me to become the founder and first president of the new Society for Economic Measurement and is the primary motivation for my recent book, Barnett (2012).

The cost of our data acquisition at Rocketdyne was enormous. The cost of the fuel and oxidizers alone was extreme, along with the other costs of the tests run daily. Our staff of statisticians had particular expertise in the statistical design of experiments. We made extensive use of Latin square designs. In addition, the rocket engines and test stands were heavily instrumented to provide us with extensive data from each test. There is no way that we could successfully have developed that rocket engine without those tests and the thousands of resulting observations on hundreds of variables. In addition, the measurements on those variables had to be made with extraordinary accuracy. 
For example, in one project that dominated my research for a year, I needed measurements of the engine's start times and the ability to predict those start times accurately to within a few milliseconds. The needed accuracy of that measurement was determined by NASA and imposed on us. The first stage of the Saturn Vehicle had five F-1 engines clustered to produce a total of 7.5 million pounds of thrust, to get the vehicle off the ground and on its way. The five engines had to start in a particular sequence, with great accuracy. An error of only milliseconds could have caused a catastrophic failure, called the "pogo effect," by which the vehicle would go into harmonic oscillations and break apart. $^{2}$ The failure of the vehicle would cause rupture of the fuel and oxidizer tanks and a resulting explosion that would have killed any astronauts unfortunate enough to have been in the command module sitting at the top of the vehicle. If you have ever seen any of the early tests of civilian or military rockets, you likely saw such explosions and thought that the rocket engine had exploded, when in fact the explosion was more likely caused by structural failure of the vehicle from pogo effect oscillations.

"Bifurcation" was discovered by the famous mathematician, Henri Poincaré (1885), for which he won the Gold Medal of the Royal Astronomical Society (1900). ${ }^{3}$ Indeed, those explosions were bifurcations. Such phenomena are well known to engineers. Consider, for example, the frequent law suits against automobile manufacturers, resulting from fatalities of drivers or passengers following bifurcations of automobile dynamics. Such bifurcations and resulting catastrophes usually are caused by very small errors in design or manufacture. ${ }^{4}$

In my opinion, here lies the source of the largest gap between rocket science and economic science. In real rocket science, engineers are fully aware of the implications of systems theory, which emphasizes that small changes in data or parameters can cause major changes in system dynamics. The cause is crossing a bifurcation boundary in parameter space. As a result, "errors in the variables" in

\footnotetext{
${ }^{2}$ Another source of the pogo effect was unstable low frequency oscillations in combustion in the engine's thrust chamber or of propellant feed at the resonant frequency of the vehicle. This problem was troublesome with the second stage engine, the J-2. With the F-1, the risk was caused by sudden compression of the fuel lines during engine start, especially of the central engine. A consequence could be fluctuations in fuel pressure through feedback.

${ }^{3} \mathrm{~A}$ bifurcation is a fundamental change in the nature of the solution path to a dynamical system, such as change from monotonic stability, to damped stability, or to unstable periodic oscillations. While many bifurcations are from stable to unstable dynamics, soft bifurcations are from one type of stable dynamics to another. There are an infinite number of types of unstable bifurcations, with chaos being a limiting case. But there are also an infinite number of soft bifurcations, such as from periodic damped stability to multiperiodic damped stability. Soft bifurcations can produce dramatically different behavior over finite lengths of time.

${ }^{4}$ I first became aware of this problem long ago, while working for the Rochester Products Division of General Motors. Tiny changes in settings or in design could produce dramatic changes in behavior, such as engine stall. The laboratory used to test new designs was instruments for extremely precise measurements.
} 
rocket science are investigated by exploring the effects of small changes of variables in data space on solution dynamics in function space, if the parameters are known. If the parameters are unknown and estimated, then the relevant mapping is from the data space to the space of stochastic processes, since the solution functions are then stochastic processes. In contrast, macroeconomists tend to look upon "errors in the variables" in terms of a mapping from one Euclidean space to another, not from one Euclidean space to a function space. For example, it is common to consider the effect of a small data error on estimates of elasticities of substitution. Small changes in the domain space of that mapping typically produce small changes in the range space of the mapping. Systems theoretic dynamical robustness is a very different matter.

Economic theorists are well aware of the consequences of bifurcation, and many theoretical papers have been published on that subject. But when policy simulations of macroeconometric models are run, they typically are run with the parameters set only at their point estimates. For example, when I was on the staff of the Federal Reserve Board, I never saw such policy simulations delivered to the Governors or to the Open Market Committee with parameters set at any points in the parameter estimators' confidence region, other than at the point estimate. This mind-set suggests to macroeconomists that small errors in data or in parameter estimates need not be major concerns, and hence emphasis on investment in measurement in macroeconomics is not at all comparable to investment in measurement in real rocket science. If macroeconomic policy simulations were conducted at various points within the confidence regions, the sensitivity of dynamical inferences to measurement would become as widely understood in economics as in rocket science.

The confidence regions of the parameter estimators of most macroeconometric models are intersected by bifurcation boundaries, producing a robustness problem for dynamical inferences. See Barnett and Chen (2015), who survey a large number of such bifurcation boundary searches over models spanning all modern classes of macroeconometric models, including recent models with rational expectations, older Keynesian models with adaptive expectations, Euler equation models with deep parameters, open economy models, endogenous growth models, new Keynesian models with Taylor rule or inflation targeting policy equation, linear models and nonlinear models, continuous time and discrete time models, and Marshallian macroeconometric models with industrial free entry, among 
others. In fact we have not succeeded in finding a single model that is not vulnerable to the problem, as would perhaps not surprise an economic theorist familiar with Grandmont's (1985) early result. ${ }^{5}$

It is tempting to blame central bank economists for this problem, as a result of their vested interest in the ability to provide unqualified policy simulation recommendations to the bank's governors. But in fact academic economists are no less to blame. I have been the editor of the Cambridge University Press journal, Macroeconomic Dynamics, since it was founded in 1997. Although that journal has published many papers containing policy simulations with parameters estimated or calibrated at a point, I rarely recall having received a submission that systematically investigated robustness of those dynamical inferences to variations of the parameters within the confidence region around the point estimate. ${ }^{6}$

Of course, it is not necessary to be a "rocket scientist" to recognize that there are serious problems with the availability and quality of macroeconomic data. Media reporters with no knowledge of bifurcation have been complaining about those data for years. For example, the following by Mandel (1994) appeared as the cover story of Business Week magazine,

"The economic statistics that the government issues every week should come with a warning sticker: User beware. In the midst of the greatest information explosion in history, the government is pumping out a stream of statistics that are nothing by myths and misinformation."

The following appeared more recently in the Economist (2015) magazine: "Established macroeconomists would do well to pay attention. They should start by being much more careful about data."

Indeed some economists have themselves been observing the problem for decades. Consider, for example, the following from Boulding (1970, p. 233): "We seem to be producing a generation of economists now, whose main preoccupation consists of analyzing data which they have not collected

\footnotetext{
${ }^{5}$ That model was an elementary classical model with rational expectations, continuous market clearing, no rigidities or market failures, perfect competition, and Cobb Douglas consumers and firms, with all solutions being Pareto optimal. Grandmont proved that the parameter space is stratified into an infinite number bifurcation subsets supporting monotonic stability at one extreme, chaos at the other extreme, and an infinite number of multiperiod solutions between. More recent models capable of producing policy relevant non-Pareto-optimal solutions can produce even more complex forms of bifurcation, as surveyed in Barnett and Chen (1985). ${ }^{6}$ Explorations of robustness to parameter estimates produced in different manners are relatively common, but such studies remain about point estimates, not about variations within the confidence region about the estimates. For example, there have been studies of new Keynesian models with Taylor rules or inflation targeting equations under various assumptions about "active" versus "passive" and forward-looking versus backward-looking rules. For surprising results from systematic investigation for bifurcation boundaries within the parameter space of such models, see section 4 of Barnett and Chen (2015).
} 
and who have no interest whatever in what might be called a data-reality function, that is, into what extent a set of data corresponds to any significant reality in the world."

\section{The Federal Reserve}

I was a research economist in the Special Studies Section of the Federal Reserve Board in Washington, D.C. for seven years. Sadly that elite research section no longer exists. While some of my most important solely authored papers were published during those years, such as Barnett (1980), collaboration in various forms is common within the Federal Reserve. Federal Reserve economists have easy access to data, assistance, and interaction with other economists. Although collaboration within the Federal Reserve is not comparable to the tightly bound collaboration of engineers within aerospace firms, collaboration within the Federal Reserve does not necessarily lead to coauthorship. For example, the Special Studies section chief, Peter Tinsley, for whom I worked, was regularly a source of information and inspiration. In addition, he strongly encouraged collaboration and was a valuable source of information about which economists on the Board's staff possessed expertise in areas relevant to my research. But I never coauthored a paper with Peter.

Coauthorship and publication were not constrained at the Federal Reserve to the same degree as at Rocketdyne, since there are no national security clearance issues. ${ }^{7}$ Nevertheless, publication is not as unconstrained as in academia. Publication in the Federal Reserve Bulletin or in a Federal Reserve regional bank's Review goes through a screening procedure at higher levels of the organization. The final published version of the article in Federal Reserve System publications might differ substantially from the authors' original submission. Screening of publications in professional academic journals was much lighter, but did exist. I do not know whether that is still the case. When screening began at the Board, while I was there, the procedure seemed puzzling.

When I first arrived at the Board, we were free to submit papers to professional journals without any internal review at all. But shortly after I arrived, an internal review requirement was implemented. Prior to submission to a journal, Federal Reserve Board staff authors had to provide the paper to a high ranking Board staff officer for review. He invariably marked some changes in wording onto the manuscript. Making those "suggested" changes was mandatory before submission to a journal. I found this review to be puzzling, since those changes rarely were substantive and never

\footnotetext{
${ }^{7}$ I did not work in the International Finance Division, which had access to $\mathrm{CIA}$ data and was subject to higher security constraints than the Division of Research and Statistics.
} 
altered the nature of my reported research or the conclusions. The changes of wording seemed trivial and harmless. As a result, I asked my section chief, Peter Tinsley, what the purpose of those changes was. The answer was surprising. I'll need to provide some relevant background before explaining this paradox.

Prior to the time that I arrived at the Board, one of the staff's best economists, William Poole, left on leave for the Federal Reserve Bank of Boston and then permanently to Brown University. Along with others, he became an outspoken critic of the Federal Reserve, frequently publishing his criticisms in the public media. Peter Tinsley told me that the seemingly harmless censorship was designed to remove or modify sentences that were worded in a manner that Poole might have found to be quotable in the American Banker, in which he had a regular byline. Considering how worried the Board and its senior staff were about Poole's publications, I was surprised many years later, when his appointment as president of the Federal Reserve Bank of St. Louis was approved by a subsequent Federal Reserve Board chairman. But it was another time and another place. The time during which the Board and its senior staff were so worried about Poole and the Fed's other critics was the 1970s --- a time of intense controversy about inflation.

Although the odd censorship of journal articles at the Board was harmless, and although the economists at the Federal Reserve normally do not have security clearances, there are nevertheless some severe constraints on Federal Reserve employees. The Federal Reserve acquires some data from private sector suppliers under confidentiality agreements. Any economist who makes any of those data public is in serious trouble. While I was there, an economist supplied to Consumer Reports magazine data on interest rates being paid by individual banks throughout the country on deposits. Although any bank will reveal that information, if asked, the "reserve file" that housed that data at the Board was acquired under a confidentiality agreement. When the Consumer Reports article appeared, Chairman Burns asked the FBI to investigate his entire staff to find the person who had provided the data to Consumer Reports. The economist who had done that, perhaps believing he had to provide the data under the Freedom of Information Act, was tracked down by the FBI and fired.

There also are security clearance issues at the Federal Reserve, but not of a sort usually evident to researchers. Federal Reserve senior staff members with access to Federal Open Market Committee (FOMC) material must be very careful. In fact, Federal Reserve Bank presidents and senior staff with access to the FOMC secure server are subject to background investigation before appointment. 
Since Federal Reserve economists publish widely and speak frequently at conferences, it is tempting to believe that the culture and attitudes are similar to those in academia. When I was at the Board, the Staff Director of Monetary Policy had the most powerful position on the Federal Reserve Board's staff. He told us "Never trust academics. They are glory seekers." Considerably more insights of that sort can be found in Barnett (2012). ${ }^{8}$

\section{Academia}

My first academic position was at the University of Texas at Austin. I was never an assistant professor or associate professor. The University of Texas hired me away from the Federal Reserve Board as a full professor with an endowed chair. Academia proved to be another world for me. There were no longer any constraints on what I could publish, and indeed collaboration usually did result in coauthorship. In accordance with the maxim, "publish or perish," the incentive to publish was clear and unconditional. Because of my intellectual origins at Rocketdyne, I immediately began collaboration with other professors and with my own PhD students, some of whom have become famous. For example, Salam Fayyad become the Prime Minister of the Palestinian Authority. In addition, I have always supervised large numbers of PhD dissertations, since I value that kind of interaction to the same degree I did at Rocketdyne, when all work was necessarily collaborative. But unfortunately I have not had access in academia to the kind of experimental data available at Rocketdyne. The potential value of such data became evident to me, when Barnett, Gallant, Hinich, Jungeilges, Kaplan, and Jensen (1997) conducted a controlled competition among tests for nonlinearity. Robustness of econometric inferences across competing tests was found to be disturbingly low.

Considering how many collaborators and coauthors I've had at the U. of Texas, at Washington University, and at the University of Kansas, I find it to be difficult to decide which to mention. Names that immediately come to mind include Apostolos Serletis, Marcelle Chauvet, Melvin Hinich, Ron Gallant, John Geweke, John Keating, Michael Belongia, and my two most productive current PhD students, Liting Su and Guo Chen. With the exception of Mike Belongia, I have coauthored papers with each of those, but indeed my interactions with Mike and his coauthor, Peter Ireland, would rank high in terms of the intellectual influences among us. My work with Paul Samuelson on the book, Inside the Economists Mind, translated into seven languages, was a unique and unforgettable experience. Others with whom I have coauthored or coedited books include Karl Shell, Kenneth Singleton, Ernst Berndt,

\footnotetext{
${ }^{8}$ Barnett (2012) won the American Publishers Award for Professional and Scholarly Excellence (the PROSE Award) for the best book published in economics during 2012.
} 
Halbert White, James Powell, George Tauchen, Andreu Mas-Colell, Jean Gabszewicz, Claude D’Apremont, Bernard Cornet, Maurice Salles, Herve Moulin, Giancarlo Gandolfo, Alan Kirman, Mark Salmon, David Hendry, Svend Hylleberg, Timo Terasvirta, and Carl Chiarella, among others. My discussions with Ilya Prigogine, Nobel Laureate in Physics at the University of Texas, influenced me in profound manners.

\section{Conclusion}

It has been a long road through many life styles. The most conspicuous differences among them have been in the nature of collaboration and publication, and the nature of the constraints on them. In terms of which experience was closest to the formal definition of science, in accordance with the "scientific method," there is no question which it was. It was at Rocketdyne, and indeed the work at Rocketdyne was the most exciting I've ever encountered. In terms of which has proven to be the most intellectually rewarding, there also is no question. It is academia. The intellectual freedom provided by academia is unmatched, and the ability to supervise and work with my own PhD students on their dissertations is deeply rewarding. My work at the Federal Reserve Board was somewhere in the middle ground, but was no less important to my life's work and to my development as a scholar.

Finally, it should be observed that institution type does not necessarily dominate collaboration experience. It is not my intention to impute my experiences at three types of institutions to everyone who has worked in central banks, universities, and high tech private firms. Beyond the influence of the research setting, collaboration tends to be idiosyncratic to personalities, including the nature of the other personalities at the institution. In fact, there is now a highly relevant new field called the "science of team science" (SciTS), dominated by psychologists. That field has its own society, running regular conferences. $^{9}$

\footnotetext{
${ }^{9}$ See www.scienceofteamscience.org/.
} 


\section{References}

Barnett, William A. (1980), "Economic Monetary Aggregates: An Application of Index Number and Aggregation Theory, "Journal of Econometrics, September, pp. 11-48.

Barnett, William A. (2012), Getting It Wrong: How Faulty Monetary Statistics Undermine the Fed, the Financial System, and the Economy, MIT Press.

Barnett, William A. and Guo Chen (2015), "Bifurcation of Macroeconometric Models and Robustness of Dynamics Inferences," Foundations and Trends in Econometrics, forthcoming.

Barnett, William A. and Paul A. Samuelson (2007), Inside the Economist's Mind: Conversations with Eminent Economists, Blackwell/Wiley Publishing.

Barnett, William A., A. R. Gallant, M. J. Hinich, J. A. Jungeilges, D. T. Kaplan, and J. J Jensen (1997), “A Single-Blind Controlled Competition among Tests for Nonlinearity and Chaos," Journal of Econometrics, vol 82, pp. 157-192.

Boulding, Kenneth E. (1970), "After Samuelson, Who Needs Adam Smith," History of Political Economy, fall 2(3), pp. 225-237.

The Economist (2015), "A Long Way from Dismal," January 10-16, vol. 414, no. 8920, p. 8.

Grandmont, J. M. (1985), “On Endogenous Competitive Business.” Econometrica, Vol. 53, pp. 9951045.

Mandel, Michael M. (1994), "The Real Truth about the Economy: Are Government Statistics So Much Pulp Fiction? Take a Look," Business Week, November 7, pp. 110-118.

Poincaré, Henri (1885), "L'Équilibre d'une Masse Fluide Animée d'un Mouvement de Rotation," Acta Mathematica 7, pp. 259-380, sept.

Fisher, Steven C. and Shamim A. Rahman (eds) (2009), Remembering the Giants: Apollo Rocket Propulsion Development, The NASA History Series, NASA History Division, National Aeronautics and Space Administration, Office of External Relations, Washington, DC.

Kraemer, Robert S. (2005), Rocketdyne: Powering Humans into Space, AIAA Education, American Institute of Aeronautics and Astronautics, Reston, VA. 